\title{
Priority selection of agro-meteorological parameters for integrated plant diseases management through analytical hierarchy process
}

\author{
Rutuja Rajendra Patil, Sumit Kumar
}

Symbiosis Institute of Technology, Symbiosis International (Deemed University), Pune, India

\begin{tabular}{l}
\hline \hline Article Info \\
\hline Article history: \\
Received Feb 10, 2021 \\
Revised Jul 16, 2021 \\
Accepted Aug 4, 2021 \\
\hline
\end{tabular}

Keywords:

Agro-meteorological parameters plant diseases Analytical hierarchy process Integrated management system

\begin{abstract}
To understand the influence of agro-meteorological parameters to take decisions related to various factors in an integrated plant disease management, it becomes vital to carry out scientific studies on the factors affecting it. The different agro-meteorological parameters namely temperature, humidity, moisture, rain, phenological week, cropping season, soil type, location, precipitation, heat index, and cloud coverage have been considered for this study. Each parameter has been allocated the ranking by using a technique called analytical hierarchical process (AHP). The parameter priorities are determined by calculating the Eigenvalues. This helps to make decisions related to integrated plant disease management where the prediction of plant disease occurrence, yield prediction, irrigation requirements, and fertilization recommendations can be taken. To take these decisions which parameters are good indicators can be identified using this method. The parameters majorly contribute to plant diseases and pest management decision making while delivers minor contribution in irrigation and fertilizer management related decision making. The manual results are compared with software generated results which indicates that both the results correlate with each other. Therefore, AHP technique can be successfully implemented for prioritizing agro-meteorological parameters for integrated plant diseases management as the results for both levels are consistent (consistency ratio $<0.1$ ).
\end{abstract}

This is an open access article under the CC BY-SA license.

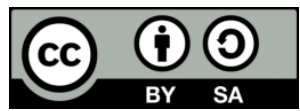

\section{Corresponding Author:}

Sumit Kumar

Symbiosis Institute of Technology, Symbiosis International (Deemed University)

Pune, India

Email: er.sumitkumar21@gmail.com

\section{INTRODUCTION}

An integrated plant disease management systems are becoming a prominent part of smart agriculture. There are certain situations where farmer's predictions about climatic conditions, crop diseases, pests, irrigation, and the yield of crop fails. The integrated plant disease management system is used to raise an alarm in situations where pests and diseases can occur in near future. Also, it provides irrigation support and recommends the fertilizers as per the requirements [1]. There are situations where the farmer must take the decision or needs to optimize the decision based on various agro-meteorological parameters [2]. Agrometeorological parameters are the factors that have an impact on climate and weather on the crops [3].

The multi-criteria decision-making method is one of the subcategories of an operation research field. Optimization is a tool for making decisions. A decision-maker must consider more than one attribute to choose alternatives from multiple options. The analytical hierarchical process (AHP), initially developed by 
Prof. Thomas L Saaty, is one of the renowned multi-criteria decision-making methods. The base of this model is linear algebra [4], [5]. In this method, initially, an AHP model is developed for the specific problem. The problem is broken down and its details are arranged hierarchically as represented in Figure 1 . The individual parameters are combined with other key parameters and different weights are assigned to the combination of different parameters. Along with the calculation of weights for each parameter to calculate their ratios is the main task of AHP. An AHP model requires a minimum of three levels. The topmost level that is Level 1 is the main objective of the decision problem. Level 2 represents the criteria or parameters for prioritizing and the third level in the hierarchy represents alternatives recommended [6], [7].

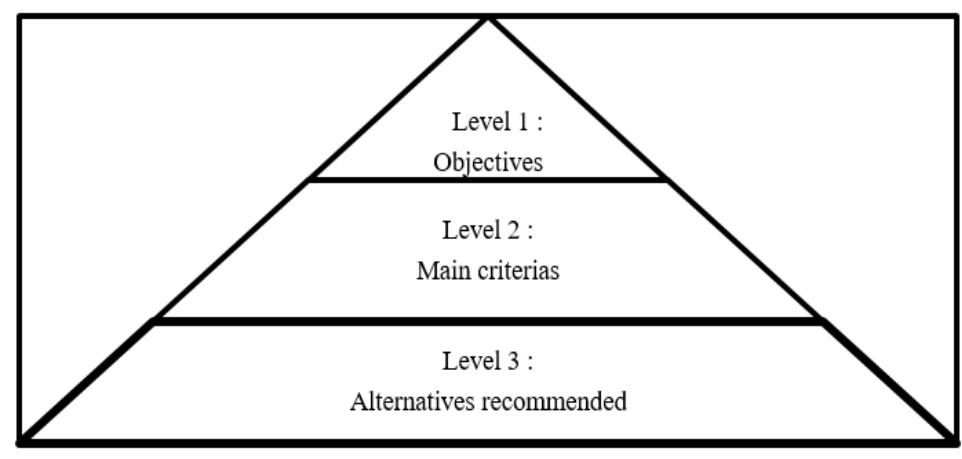

Figure 1. Generalized analytical hierarchical process (AHP) model

Tian et al. [8] have used techniques such as AHP, technique for order performance by similarity to ideal solution (TOPSIS), and gray correlation (GC) to assess the green design alternatives performance. A case study to choose the best design alternative for a refrigerator is taken under consideration. $\mathrm{Xu}$ et al. [9] have applied the concept of AHP to a new dimension of the teaching world where the evaluation of teaching performance can be gauged on a smart campus. The attributes to be considered for evaluation were selected by the principal component analysis (PCA) method. The combined technique of AHP along with TOPSIS is used to evaluate the teaching performance. Ter Chang et al. [10] discusses AHP method applied to businessto-business sector wherein the evaluation of best choice of smartphones along with the best mobile bill plans suitable for taxi drivers provided by service providers of mobile are selected. The new approach of graph theory and matrix approach (GTMA) is used to acquire values of attribute weights. The manuscript compares the performance of three techniques namely AHP, TOPSIS, and GTMA, where GTMA outstands to achieve the objective under consideration. The studies [11], [12] have used an integrated approach of AHP and vlse kriterijumska optimizacija kompromisno resenje (VIKOR) where AHP is used to calculate weights and VIKOR is used for ranking the alternatives. Zhang et al. [13] have proposed an AHP based model to predict landslides based on 9 major factors in the Pearl River Delta area of China. Zhang et al. [14] says that decision making is important these days related to traffic activities on the road. To reach from one place to another place there are multiple paths, so which alternative way to be chosen for traveling is proposed in the manuscript. Attribute weights are calculated using AHP. Muhammad et al. [15] identifies and prioritizes the parameters in an environment of e-learning that violates the integrity in academics in the universities of Saudi. The information was collected from the experts by using the Delphi method of data collection and this information was later combined with AHP for ranking the factors that affect integrity at the university level in Saudi Arabia. The manuscript [16] has used a new approach best worst method (BWM) to select one best service provider that provides cloud services out of the multiple choices available. The results of this approach are compared with the traditional AHP technique, and it is concluded that BWM proves to be the best method to choose the best provider of cloud service. Rathee et al. [17] focus on the internet of vehicles which means taking decisions related to vehicles on a real-time basis. The ensemble approach of the VIKOR technique and AHP is used to make decisions related to data processing and transferring via different sensors. Al-Zahrani [18] have applied the combined approach of analytical network process (ANP), fuzzy sets (FS), and TOPSIS to evaluate the security of the software that is used in healthcare applications in Mecca, Saudi Arabia.

After reviewing the above research papers related to multi-criteria decision-making techniques, it can be said the decision-makers can be helped with techniques to make good decisions. There are many approaches such as AHP, ANP, FS, TOPSIS used to rank the attributes of the problem to be considered. Also, many ensemble approaches have been applied to evaluate different alternatives. AHP is one of the most 
renowned techniques applied to many paradigms of society namely healthcare, manufacturing, education, and traffic management. There is very little literature available that is applied to the agricultural sector with these Multiple-criteria decision-making (MCDM) techniques. This becomes the motivation to apply MCDM techniques to the agriculture sector.

The organization of this research is namely introductory details are given in section 1 , section 2 gives details about the used method for analyzing problem under consideration at level 1, section 3 shows comparison analysis for level 1, section 4 gives details about the used method for analyzing alternatives of the problem under consideration at level 1, section 5 depicts comparison analysis for level 1, section 6 concludes the manuscript, and lastly the references used in the manuscript are cited.

\section{METHOD USED FOR ANALYZING THE PROBLEM (LEVEL: 1)}

The data was gathered for the geographical location of Dapoli Taluka in Ratnagiri district (Maharashtra, India) which is one of the high rice producing districts in the state. The dataset was created using data from the Indian Meteorological Department, the online visual crossing weather website, and the all India coordinated research project on agro meteorology (AICRPAM). The dataset contains historical weather data for 30 years from 1989 to 2019. As per standards of the Indian Meteorological Department, the week wise data for agro-meteorological parameters such as temperature, relative humidity, precipitation, wind speed, and other variables are included in the dataset. Based on the values of the parameters, the prediction of diseases and pests on the crop is made. Its yield management, alternatives for irrigation support that whether water is to be supplied to the crop or not, and also the recommendation of fertilizer is made.

\subsection{Structuring of the problem}

An AHP model about the problem under consideration in this manuscript is depicted in Figure 2 where the details are arranged hierarchically. Level 1 represents the objective of the respective analysis which is to prioritize the agro-meteorological parameters for integrated plant diseases management. Level 1 represents various agro-meteorological parameters such as location (L), phenological week (PW), cropping season $(\mathrm{CS})$, temperature $(\mathrm{T})$, relative humidity $(\mathrm{RH})$, moisture $(\mathrm{M})$, rain $(\mathrm{R})$, precipitation $(\mathrm{P})$, heat index (HI), soil type (ST) and cloud coverage (CC) [19]-[22]. The final level i.e Level 2 represents different types of plant disease management system alternatives such as diseases and pests management, irrigation management, crop yield management, and fertilizer management.

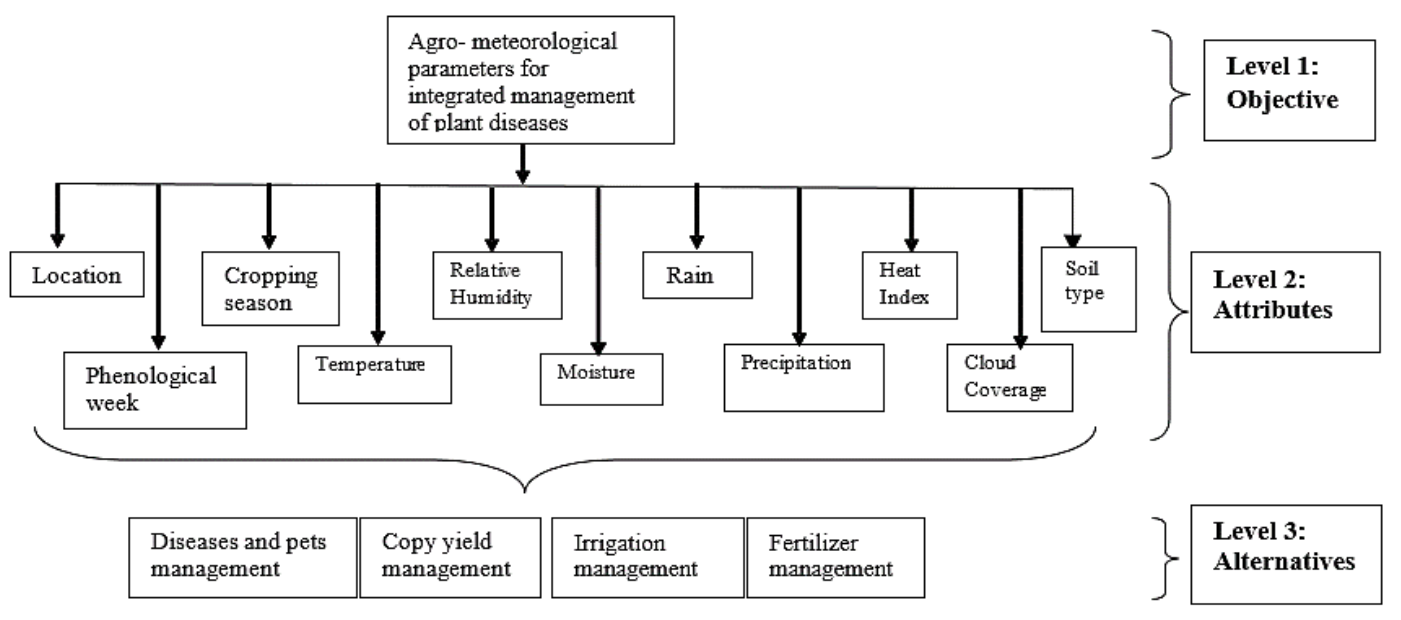

Figure 2. AHP model and its levels for prioritizing agro-meteorological parameters

\subsection{Determining the relative importance of various attributes concerning the goal}

In this section, a pairwise comparison matrix is created. This matrix helps to find the relative importance of various attributes concerning the objective. For example, the following agro-meteorological parameters matrix reads as how important is parameter Location or what is the importance of Temperature parameter while creating an integrated management system for plant diseases? Table 1 indicates the various agro-meteorological parameters to create a pair-wise comparison matrix for the problem under consideration.

The length of a pairwise matrix is equivalent to the number of parameters used in the process of decision making. To achieve the objective of prioritizing agro-meteorological parameters for plant disease 
integrated management, eleven parameters are taken under consideration, therefore the length of a pairwise matrix is $11 \times 11$ matrix. The value in the pair wise matrix was decided by consulting farmers, agriculture experts, and professors from few agriculture institutes. For these certain questions were asked to the respondents such as how important parameter location with respect to moisture parameter is. As per the responses from respondents, the pair-wise matrix calculation is performed.

This pairwise comparison matrix is created by using the scale of relative importance developed by Prof. Thomas L. Saaty. The diagrammatic representation of Saaty's scale is represented in Figure 3. Table 2 summarizes the representation of Saaty's scale in tabular form.

Table 1. Attributes to be considered to create pair-wise comparison matrix for the study

\begin{tabular}{|c|c|c|c|c|c|c|c|c|c|c|c|}
\hline $\begin{array}{l}\text { Attribute } \\
\text { number }\end{array}$ & 1 & 2 & 3 & 4 & 5 & 6 & 7 & 8 & 9 & 10 & 11 \\
\hline $\begin{array}{l}\text { Agro- } \\
\text { meteorological } \\
\text { parameters } \\
\text { name }\end{array}$ & Location & $\begin{array}{l}\text { Phenological } \\
\text { week }\end{array}$ & $\begin{array}{c}\text { Cropping } \\
\text { season }\end{array}$ & Temperature & $\begin{array}{l}\text { Relative } \\
\text { Humidity }\end{array}$ & Moisture & Rain & $\begin{array}{l}\text { Heat } \\
\text { Index }\end{array}$ & Precipitatior & $\begin{array}{l}\text { Soil } \\
\text { Type }\end{array}$ & $\begin{array}{c}\text { Cloud } \\
\text { Coverage }\end{array}$ \\
\hline
\end{tabular}

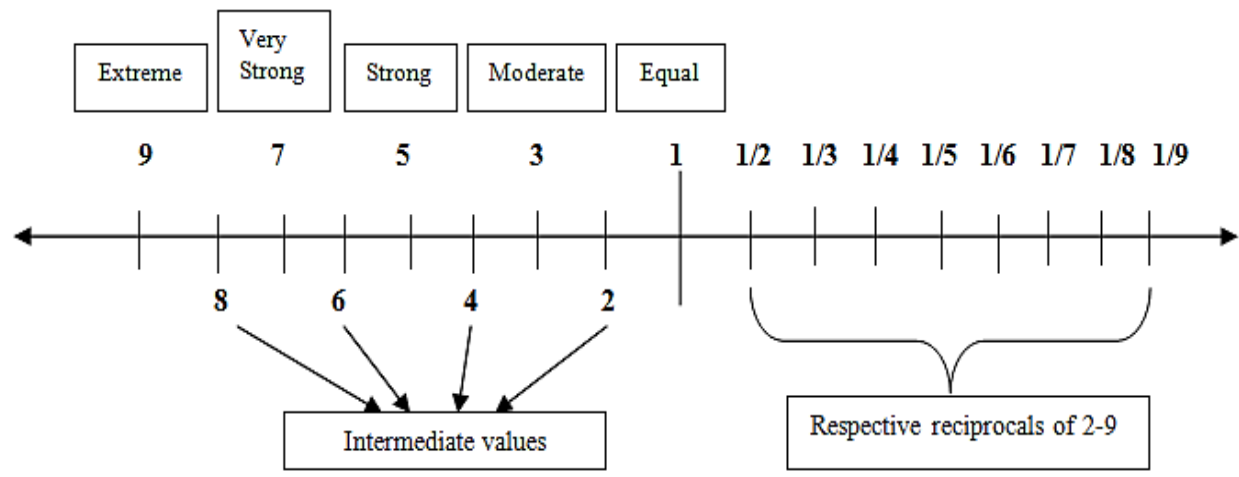

Figure 3. Representation of Saaty's scale of relative importance

Table 2. Saaty's scale of relative importance

\begin{tabular}{|c|c|c|}
\hline 3 & Moderately important & One out of the two parameters is slightly more important than the another parameter \\
\hline 5 & Strongly important & One out of the two parameters is strongly more important than the another parameter \\
\hline 7 & Very strongly important & $\begin{array}{l}\text { One out of the two parameters is very strongly more important than the another } \\
\text { parameter }\end{array}$ \\
\hline $2,4,6,8$ & $\begin{array}{l}\text { Intermediate values of } \\
\text { importance }\end{array}$ & These values are used to represent compromise between the above values \\
\hline$(1 / 2$ to $1 / 9)$ & Reciprocals & $\begin{array}{l}\text { If one of the parameters has nonzero numbers assigned to it when compared with } \\
\text { another parameter, then the other parameter will have the reciprocal value when } \\
\text { compared with the first one }\end{array}$ \\
\hline
\end{tabular}

Location is strongly important than moisture. Strongly important has the value as 5 in Saaty's scale. So, if moisture is given $\mathrm{x}$ value, then location will have $5 \mathrm{x}$ value which clearly states that location is strongly important than moisture. Therefore, the ratio of the importance of location versus the importance of moisture is 5. As opposed to this, the importance of moisture to the importance of location will give 1/5 which is the reciprocal of five. Similarly, the value for each cell is calculated and assigned to it. By observing the comparison matrix, it can be stated that all the diagonal elements are having a value of 1 because the criterion when compared to itself, is always one. Also, the upper triangular matrix is to be entered and the lower triangular matrix is the reciprocal of the upper one. The pair-wise matrix calculation of the values is represented in Table 3. 
Table 3. $11 \mathrm{X} 11$ pair-wise comparison matrix for the considered problem

\begin{tabular}{cccccccccccc}
\hline & $\mathrm{L}$ & $\mathrm{PW}$ & $\mathrm{CS}$ & $\mathrm{ST}$ & $\mathrm{T}$ & $\mathrm{RH}$ & $\mathrm{M}$ & $\mathrm{R}$ & $\mathrm{P}$ & $\mathrm{HI}$ & $\mathrm{CC}$ \\
\hline $\mathrm{L}$ & 1 & 2 & 3 & 4 & 3 & 4 & $5 \mathrm{x} / \mathrm{x}=5$ & 6 & 7 & 8 & 9 \\
$\mathrm{PW}$ & $1 / 2$ & 1 & 3 & 2 & 3 & 7 & 6 & 6 & 5 & 9 & 9 \\
$\mathrm{CS}$ & $1 / 3$ & $1 / 3$ & 1 & 2 & 3 & 3 & 4 & 5 & 6 & 7 & 8 \\
$\mathrm{ST}$ & $1 / 4$ & $1 / 2$ & $1 / 2$ & 1 & 3 & 4 & 5 & 6 & 7 & 8 & 9 \\
$\mathrm{~T}$ & $1 / 3$ & $1 / 3$ & $1 / 3$ & $1 / 3$ & 1 & 3 & 4 & 5 & 6 & 7 & 8 \\
$\mathrm{RH}$ & $1 / 4$ & $1 / 7$ & $1 / 3$ & $1 / 4$ & $1 / 3$ & 1 & 3 & 4 & 5 & 6 & 7 \\
$\mathrm{M}$ & $\mathrm{x} / 5 \mathrm{x}=1 / 5$ & $1 / 6$ & $1 / 4$ & $1 / 5$ & $1 / 4$ & $1 / 3$ & 1 & 2 & 2 & 6 & 7 \\
$\mathrm{R}$ & $1 / 6$ & $1 / 6$ & $1 / 5$ & $1 / 6$ & $1 / 5$ & $1 / 4$ & $1 / 2$ & 1 & 2 & 5 & 4 \\
$\mathrm{P}$ & $1 / 7$ & $1 / 5$ & $1 / 6$ & $1 / 7$ & $1 / 6$ & $1 / 5$ & $1 / 2$ & $1 / 2$ & 1 & 4 & 3 \\
$\mathrm{HI}$ & $1 / 8$ & $1 / 9$ & $1 / 7$ & $1 / 8$ & $1 / 7$ & $1 / 6$ & $1 / 6$ & $1 / 5$ & $1 / 4$ & 1 & 2 \\
$\mathrm{CC}$ & $1 / 9$ & $1 / 9$ & $1 / 8$ & $1 / 9$ & $1 / 8$ & $1 / 7$ & $1 / 7$ & $1 / 4$ & $1 / 3$ & $1 / 2$ & 1 \\
\hline
\end{tabular}

\subsubsection{Summation of each column in the matrix}

The fractional value of each cell is converted to a decimal value. The sum of each value in the respective column is calculated and updated in the last row of the table. Table 4 represents these computations.

Table 4. Summation of each column in $11 \mathrm{X} 11$ pair-wise comparison matrix

\begin{tabular}{|c|c|c|c|c|c|c|c|c|c|c|c|}
\hline & $\mathrm{L}$ & PW & $\mathrm{CS}$ & ST & $\mathrm{T}$ & $\mathrm{RH}$ & $\mathrm{M}$ & $\mathrm{R}$ & $\mathrm{P}$ & $\mathrm{HI}$ & $\mathrm{CC}$ \\
\hline $\mathrm{L}$ & 1 & 2 & 3 & 4 & 3 & 4 & 5 & 6 & 7 & 8 & 9 \\
\hline PW & 0.5 & 1 & 3 & 2 & 3 & 7 & 6 & 6 & 5 & 9 & 9 \\
\hline $\mathrm{CS}$ & 0.333333 & 0.333333 & 1 & 2 & 3 & 3 & 4 & 5 & 6 & 7 & 8 \\
\hline ST & 0.25 & 0.5 & 0.5 & 1 & 3 & 4 & 5 & 6 & 7 & 8 & 9 \\
\hline $\mathrm{T}$ & 0.333333 & 0.333333 & 0.333333 & 0.333333 & 1 & 3 & 4 & 5 & 6 & 7 & 8 \\
\hline RH & 0.25 & 0.142857 & 0.333333 & 0.25 & 0.333333 & 1 & 3 & 4 & 5 & 6 & 7 \\
\hline M & 0.2 & 0.166667 & 0.25 & 0.2 & 0.25 & 0.333333 & 1 & 2 & 2 & 6 & 7 \\
\hline $\mathrm{R}$ & 0.166667 & 0.166667 & 0.2 & 0.166667 & 0.2 & 0.25 & 0.5 & 1 & 2 & 5 & 4 \\
\hline $\mathrm{P}$ & 0.142857 & 0.2 & 0.166667 & 0.142857 & 0.166667 & 0.2 & 0.5 & 0.5 & 1 & 4 & 3 \\
\hline HI & 0.125 & 0.111111 & 0.142857 & 0.125 & 0.142857 & 0.166667 & 0.166667 & 0.2 & 0.25 & 1 & 2 \\
\hline $\mathrm{CC}$ & 0.111111 & 0.111111 & 0.125 & 0.111111 & 0.125 & 0.142857 & 0.142857 & 0.25 & 0.33333 & 0.5 & 1 \\
\hline Sum & 3.412301 & 5.065079 & 9.05119 & 10.32897 & 14.21786 & 23.09286 & 29.30952 & 35.95 & 41.5833 & 61.5 & 67 \\
\hline
\end{tabular}

\subsubsection{Computing eigenvalue and eigen vector}

After summation of all the individual columns of the matrix, a normalized pair wise matrix is calculated. In this section, each cell of the respective column in Table 4 is divided by the sum of the respective column, and the value is updated in the corresponding cell of Table 5. For instance, each cell in the first column with label L will be divided by the Sum value of the L column i.e. 1/3.412301, 0.5/3.412301, $0.25 / 3.412301$, and so on. This method is followed by all other columns. The summation value of each column is 1 . Table 5 represents these computations.

\subsubsection{Obtaining the normalized principal Eigenvector or calculating criteria weights}

The criteria weights are calculated by averaging all the elements in the row. Each row in Table 5 is added up and the total sum is divided by the number of parameters. Here the number of parameters is 11 . For instance, if we consider first row to calculate criteria weights, it is calculated as:

\section{$(0.293057+0.394861+0.331448+0.38726+0.211002+0.173214+0.170593+0.166898+0.168337+$ $0.130081+0.134328) / 11=0.232825$.}

hence, 0.232825 is the criteria weight for the first row of the table. Similarly, for all other ten rows, criteria weights are calculated. Table 6 shows the criterion weight table for all eleven parameters.

\subsection{Calculate consistency ratio}

To check whether the calculated values are correct or not, a consistency test needs to be carried out. The three components are calculated namely: The principal Eigenvalue $(\lambda \max )$, consistency index $(\mathrm{CI})$, and consistency ratio $(\mathrm{CR})$. For performing this calculation, the initial pair-wise comparison matrix that is not normalized needs to be considered. Here each value in the column is multiplied by the criteria value. The calculation of the first column of the table with label $\mathrm{L}$ is displayed in Table 7, where each cell in the first column is multiplied by the first-row value of the criteria weight. This calculation is repeated for all other parameters. 
Table 5. Division of each cell in the column with the sum of the corresponding column

\begin{tabular}{|c|c|c|c|c|c|c|c|c|c|c|c|}
\hline & $\mathrm{L}$ & PW & $\mathrm{CS}$ & ST & $\mathrm{T}$ & RH & $\mathrm{M}$ & $\mathrm{R}$ & $\mathrm{P}$ & $\mathrm{HI}$ & $\mathrm{CC}$ \\
\hline \multirow[t]{2}{*}{$\mathrm{L}$} & 0.293 & 0.3948 & 0.3314 & 0.3872 & 0.2110 & 0.1732 & 0.1705 & 0.1668 & 0.1683 & 0.1300 & 0.1343 \\
\hline & 057 & 61 & 48 & 6 & 02 & 14 & 93 & 98 & 37 & 81 & 28 \\
\hline \multirow[t]{2}{*}{ PW } & 0.146 & 0.1974 & 0.3314 & 0.1936 & 0.2110 & 0.3031 & 0.2047 & 0.1668 & 0.1202 & 0.1463 & 0.1343 \\
\hline & 529 & 3 & 48 & 3 & 02 & 24 & 12 & 98 & 4 & 41 & 28 \\
\hline \multirow[t]{2}{*}{$\mathrm{CS}$} & 0.097 & 0.0658 & 0.1104 & 0.1936 & 0.2110 & 0.1299 & 0.1364 & 0.1390 & 0.1442 & 0.1138 & 0.1194 \\
\hline & 686 & 1 & 83 & 3 & 02 & 1 & 74 & 82 & 89 & 21 & 03 \\
\hline \multirow[t]{2}{*}{ ST } & 0.073 & 0.0987 & 0.0552 & 0.0968 & 0.2110 & 0.1732 & 0.1705 & 0.1668 & 0.1683 & 0.1300 & 0.1343 \\
\hline & 264 & 15 & 41 & 15 & 02 & 14 & 93 & 98 & 37 & 81 & 28 \\
\hline \multirow[t]{2}{*}{$\mathrm{T}$} & 0.097 & 0.0658 & 0.0368 & 0.0322 & 0.0703 & 0.1299 & 0.1364 & 0.1390 & 0.1442 & 0.1138 & 0.1194 \\
\hline & 686 & 1 & 28 & 72 & 34 & 1 & 74 & 82 & 89 & 21 & 03 \\
\hline \multirow[t]{2}{*}{ RH } & 0.073 & 0.0282 & 0.0368 & 0.0242 & 0.0234 & 0.0433 & 0.1023 & 0.1112 & 0.1202 & 0.0975 & 0.1044 \\
\hline & 264 & 04 & 28 & 04 & 45 & 03 & 56 & 66 & 4 & 61 & 78 \\
\hline \multirow[t]{2}{*}{$\mathrm{M}$} & 0.058 & 0.0329 & 0.0276 & 0.0193 & 0.0175 & 0.0144 & 0.0341 & 0.0556 & 0.0480 & 0.0975 & 0.1044 \\
\hline & 611 & 05 & 21 & 63 & 84 & 34 & 19 & 33 & 96 & 61 & 78 \\
\hline \multirow[t]{2}{*}{$\mathrm{R}$} & 0.048 & 0.0329 & 0.0220 & 0.0161 & 0.0140 & 0.0108 & 0.0170 & 0.0278 & 0.0480 & 0.0813 & 0.0597 \\
\hline & 843 & 05 & 97 & 36 & 67 & 26 & 59 & 16 & 96 & 01 & 01 \\
\hline \multirow[t]{2}{*}{$\mathrm{P}$} & 0.041 & 0.0394 & 0.0184 & 0.0138 & 0.0117 & 0.0086 & 0.0170 & 0.0139 & 0.0240 & 0.0650 & 0.0447 \\
\hline & 865 & 86 & 14 & 31 & 22 & 61 & 59 & 08 & 48 & 41 & 76 \\
\hline \multirow[t]{2}{*}{$\mathrm{HI}$} & 0.036 & 0.0219 & 0.0157 & 0.0121 & 0.0100 & 0.0072 & 0.0056 & 0.0055 & 0.0060 & 0.0162 & 0.0298 \\
\hline & 632 & 37 & 83 & 02 & 48 & 17 & 86 & 63 & 12 & 6 & 51 \\
\hline \multirow[t]{2}{*}{$\mathrm{CC}$} & 0.032 & 0.0219 & 0.0138 & 0.0107 & 0.0087 & 0.0061 & 0.0048 & 0.0069 & 0.0080 & 0.0081 & 0.0149 \\
\hline & 562 & 37 & 1 & 57 & 92 & 86 & 74 & 54 & 16 & 3 & 25 \\
\hline
\end{tabular}

Table 6. Criteria weights calculation for 11 parameters

\begin{tabular}{cc}
\hline Agro-meteorological parameters & Criteria Weights \\
\hline L & 0.232825 \\
PW & 0.195971 \\
CS & 0.132872 \\
ST & 0.134408 \\
T & 0.098719 \\
RH & 0.069559 \\
M & 0.0464 \\
R & 0.034441 \\
P & 0.027165 \\
HI & 0.01519 \\
CC & 0.012449 \\
\hline
\end{tabular}

Table 7. Calculation of values for weighted sum matrix for location (L) parameter

\begin{tabular}{ccccc}
\hline $\mathrm{L}$ & $*$ & Criteria weight for L & $=$ & Corresponding values for weighted sum matrix \\
\hline 1 & $*$ & 0.232825479 & $=$ & 0.232825 \\
0.5 & $*$ & 0.232825479 & $=$ & 0.116413 \\
0.333333 & $*$ & 0.232825479 & $=$ & 0.077608 \\
0.25 & $*$ & 0.232825479 & $=$ & 0.058206 \\
0.333333 & $*$ & 0.232825479 & $=$ & 0.077608 \\
0.25 & $*$ & 0.232825479 & $=$ & 0.058206 \\
0.2 & $*$ & 0.232825479 & $=$ & 0.046565 \\
0.166667 & $*$ & 0.232825479 & $=$ & 0.038804 \\
0.142857 & $*$ & 0.232825479 & $=$ & 0.033261 \\
0.125 & $*$ & 0.232825479 & $=$ & 0.029103 \\
0.11111 & $*$ & 0.232825479 & $=$ & 0.025869 \\
\hline
\end{tabular}

\subsubsection{Calculating weighted sum value}

After computing the corresponding values for all 11 rows of the matrix by multiplying the parameter value and criteria weight for that parameter. The weighted sum value is calculated by taking the sum of each value in the row. The calculation is done for the first row. Rest ten calculations are performed in a similar way.

$0.232825+0.391943+0.398616+0.537633+0.296157+0.278236+0.232002+0.206644+0.190153+0.1$ $21521+0.112045=2.997774$.

The Table 8 shows the weighted sum values for all 11 parameters. 


\subsubsection{Calculate the ratio of weighted sum value and criteria weight for each row}

Table 9 shows the ratio of weighted sum value and Criteria weight for each row in the table.

Table 8. Calculation of weighted sum values

\begin{tabular}{c} 
for 11 parameters \\
\hline Weighted sum value \\
\hline 2.997774 \\
2.632511 \\
1.776173 \\
1.793794 \\
1.266141 \\
0.857634 \\
0.535091 \\
0.395294 \\
0.309861 \\
0.173858 \\
0.145802 \\
\hline
\end{tabular}

Table 9. Ratio of weighted sum value and criteria weights

\begin{tabular}{c} 
Weighted sum value/Criteria weights \\
\hline $2.997774 / 0.232825=12.87563$ \\
$2.632511 / 0.195971=13.43315$ \\
$1.776173 / 0.132872=13.36757$ \\
$1.793794 / 0.134408=13.34587$ \\
$1.266141 / 0.098719=12.82571$ \\
$0.857634 / 0.069559=12.3296$ \\
$0.535091 / 0.0464=11.53203$ \\
$0.395294 / 0.034441=11.47754$ \\
$0.309861 / 0.027165=11.40675$ \\
$0.173858 / 0.01519=11.44545$ \\
$0.145802 / 0.012449=11.71156$ \\
\hline
\end{tabular}

\subsubsection{Compute ( $\lambda$ max), $C I$ and $C R$ values}

The Eigenvalues $(\lambda \max )$ can be calculated by calculating the average of the values obtained by taking the ratio of weighted sum value and criteria value as shown in Table 9. So here,

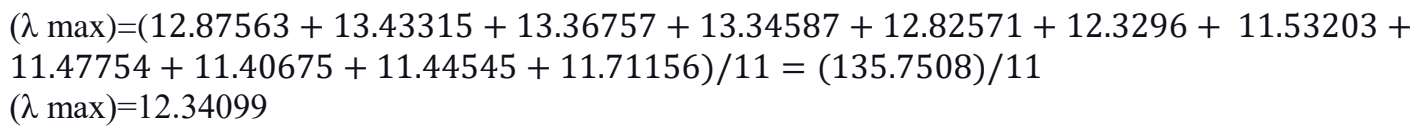

The consistency index i.e. CI is calculated by using following formula:

$$
\text { Consistency Index }(C I)=(\lambda \max -n) /(n-1)
$$

where ' $n$ ' is the number of parameters to be compared.

$$
C I=(12.34099-11) /(11-1)=(1.34099) /(10)
$$

Therefore, $\mathrm{CI}=0.134099$.

Finally, the consistency ratio (CR) is calculated. For this random index for 11 parameters that are available publicly in the form of a table is used. There are various values of RI simulated by different researchers for a different number of parameters. However, in this study, RI considered is 1.576 as per Oak Ridge simulations [23].

$$
\begin{aligned}
& \text { Consistency Ratio }(C R)=\text { Consistency Index }(C I) / \text { Random Index }(R I) \\
& \mathrm{CR}=0.134099 / 1.576=0.085088=8.5 \% \text {. }
\end{aligned}
$$

Since the value of CR is $0.085088<0.10$ which is a standard. Thus, it can be assumed that the pairwise matrix is reasonably consistent. Therefore, it can be concluded that AHP is suitable method for prioritizing the agro-meteorological parameters in agriculture management.

\section{ANALYSIS OF THE RESULTS FOR LEVEL 1 PROPOSED WORK}

The computed results in section 2 are then compared with results generated by AHP software [24] to make it more rational as displayed in Table 10. AHP software performed 55 pairwise comparisons based on the weights of the criteria. It calculated principal Eigenvalue $=12.298$ and consistency ratio $\mathrm{CR}=8.6 \%$ while the manual calculation provided values as 12.34099 for principal Eigenvalue and $8.5 \%$ for consistency ratio. In Figure 4, the green bars show the rankings of the parameters. It can be concluded that the location where the crop is being planted will have the highest weightage to predict the plant diseases. The Phenological week is the meteorological week in which the crop growth is at its current state which is followed by location. The pie chart in Figure 5 represents the importance of agro-meteorological parameters. The proportion of each parameter is given here. 
Consolidated Result

$\square_{\min } \boldsymbol{R}_{\text {Result }} \square_{\max }$

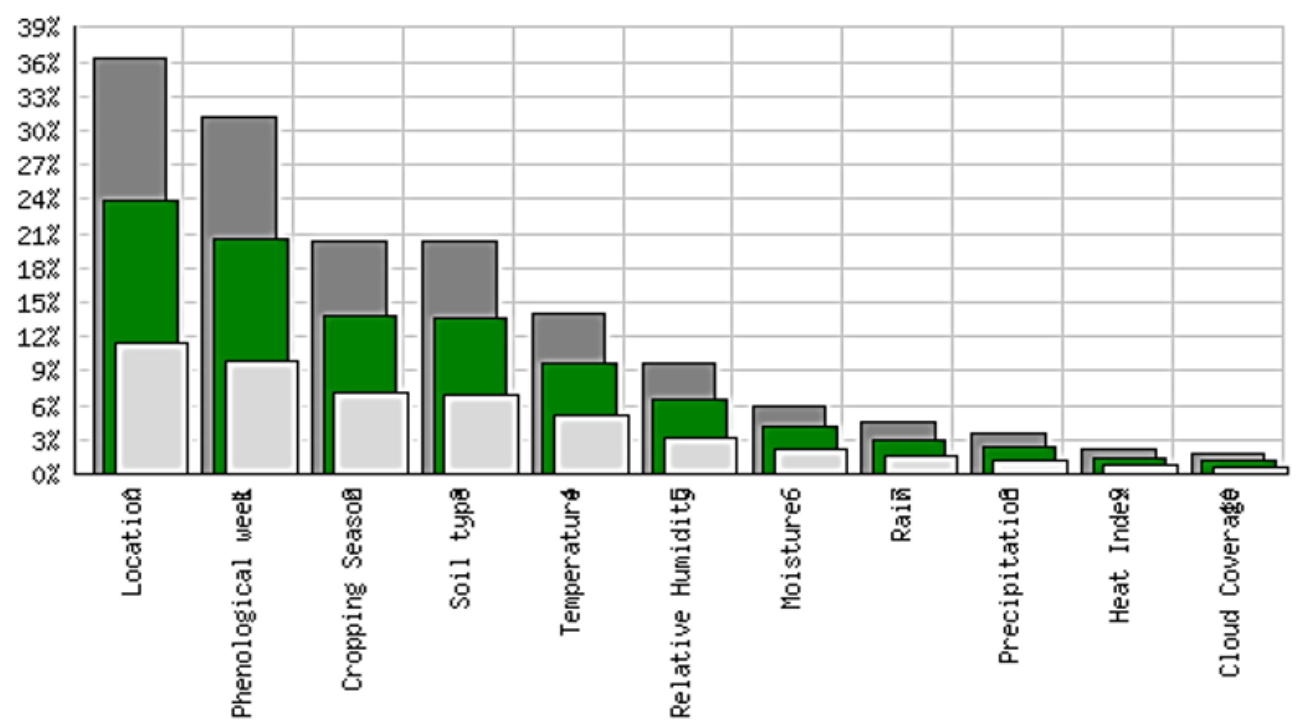

Figure 4. Consolidated result of parameter priorities based on pair wise comparison

Table 10. Results of manual calculations showing resemblance with AHP software

\begin{tabular}{ccc}
\hline Parameter & Manually calculated criteria weights & AHP software calculated criteria weights \\
\hline Agro-meteorological parameters prioritization & 100.00 & 100.00 \\
Location & 23.2825 & 23.8 \\
Phenological week & 19.5971 & 20.6 \\
Cropping season & 13.2872 & 13.8 \\
Soil type & 13.4408 & 13.7 \\
Temperature & 9.8719 & 9.6 \\
Relative Humidity & 6.9559 & 6.5 \\
Moisture & 4.64 & 4.1 \\
Rain & 3.4441 & 3.0 \\
Precipitation & 2.7165 & 2.4 \\
Heat Index & 1.519 & 1.4 \\
Cloud coverage & 1.2449 & 1.2 \\
& $100 \%$ & $100 \%$ \\
\hline
\end{tabular}

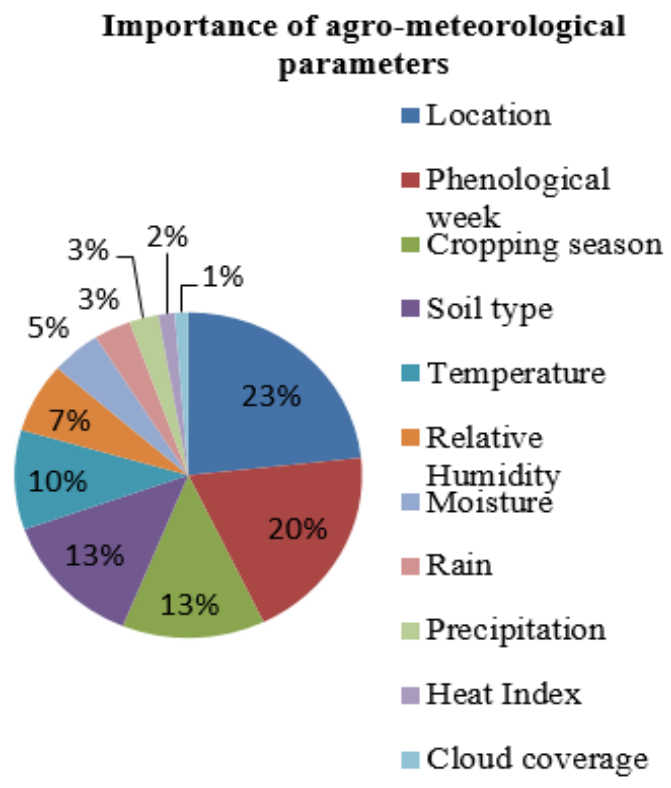

Figure 5. Pie chart representing the proportions of agro-meteorological parameters 


\section{METHOD FOR ALTERNATIVES (LEVEL 2)}

At this level, the following four alternatives are generated for integrated plant disease management: i) Disease and Pest management (DP); ii) Irrigation management (I); iii) Crop yield management (CY); and iv) Fertilizer management $(\mathrm{F})$. The section will help to understand which agro-meteorological parameters will be more important in achieving the various alternatives. The analytical hierarchical process technique is applied to Level 2 and it's stepwise (step 1-step 3) manual computations are shown in section 4.

Step 1: Structuring of the problem for level 2

Figure 2 in section 2 shows the hierarchical AHP representation model for level 2.

Step 2: Determining the relative importance of various alternatives in level 2 with respect to the goal

Table 11 represents this step.

Step 2.1: Summation of each column in the matrix

Table 12 represents this step.

Step 2.2: Calculation of normalized pair wise matrix

The calculations of normalized pair wise matrix for second level is represented in Table 13. Table 14 is the resultant normalized pairwise matrix derived from Table 13.

Step 2.3: Obtaining the principal Eigen vector or calculating criteria weights

The weight calculation for each second level criteria is represented in Table 15.

Table 11. Matrix for calculating weights for alternatives

\begin{tabular}{ccccc}
\hline Alternatives & DP & I & CY & F \\
\hline DP & 1 & 5 & 7 & 9 \\
I & $1 / 5$ & 1 & 2 & 3 \\
CY & $1 / 7$ & $1 / 2$ & 1 & 5 \\
F & $1 / 9$ & $1 / 3$ & $1 / 5$ & 1 \\
\hline
\end{tabular}

Table 12. Conversion of fractional values and summation of each column

\begin{tabular}{ccccc}
\hline Alternatives & DP & I & CY & F \\
\hline DP & 1 & 5 & 7 & 9 \\
I & 0.2 & 1 & 2 & 3 \\
CY & 0.142857 & 0.5 & 1 & 5 \\
F & 0.111111 & 0.333333 & 0.2 & 1 \\
Sum & 1.453968 & 6.833333 & 10.2 & 18 \\
\hline
\end{tabular}

Table 13. Normalized pairwise matrix for alternative level

\begin{tabular}{ccccc}
\hline Alternatives & DP & I & CY & F \\
\hline DP & $1 / 1.453968$ & $5 / 6.833333$ & $7 / 10.2$ & $9 / 18$ \\
I & $0.2 / 1.453968$ & $1 / 6.833333$ & $2 / 10.2$ & $3 / 18$ \\
CY & $0.142857 / 1.453968$ & $0.5 / 6.833333$ & $1 / 10.2$ & $5 / 18$ \\
F & $0.111111 / 1.453968$ & $0.3333333 / 6.833333$ & $0.2 / 10.2$ & $1 / 18$ \\
\hline
\end{tabular}

Table 14. Resultant normalized pair-wise matrix

\begin{tabular}{ccccc}
\hline Alternatives & DP & I & CY & F \\
\hline DP & 0.687773 & 0.731707 & 0.686275 & 0.5 \\
I & 0.137555 & 0.146341 & 0.196078 & 0.166667 \\
CY & 0.098253 & 0.073171 & 0.098039 & 0.277778 \\
F & 0.076419 & 0.04878 & 0.019608 & 0.055556 \\
\hline
\end{tabular}

Table 15. Criteria weight calculations

\begin{tabular}{cccccc}
\hline Alternatives & DP & I & CY & F & Criteria weights \\
\hline DP & 0.687773 & 0.731707 & 0.686275 & 0.5 & 0.651439 \\
I & 0.137555 & 0.146341 & 0.196078 & 0.166667 & 0.16166 \\
CY & 0.098253 & 0.073171 & 0.098039 & 0.277778 & 0.13681 \\
F & 0.076419 & 0.04878 & 0.019608 & 0.055556 & 0.050091 \\
\hline
\end{tabular}

Step 3: Calculate consistency ratio

Table 16 represents the weighted sum value for second level criteria. Table 17 shows the resultant matrix of weighted sum value. The ratio of weighted sum value and criteria weights are calculated and represented in Table 18. 
Table 16. Calculating weighted sum value

\begin{tabular}{ccccc}
\hline Alternatives & DP X 0.651439 & I X 0.16166 & CY X 0.13681 & F X 0.050091 \\
\hline DP & $1 \times 0.651439$ & $5 \times 0.16166$ & $7 \times 0.13681$ & 9 \\
I & $0.2 \times 0.651439$ & $1 \times 0.16166$ & $2 \times 0.13681$ & 3 \\
CY & $0.142857 \times 0.651439$ & $0.5 \times 0.16166$ & $1 \times 0.13681$ & 5 \\
F & $0.111111 \times 0.651439$ & $0.333333 \times 0.16166$ & $0.2 \times 0.13681$ & 1 \\
\hline
\end{tabular}

Table 17. Resultant weighted sum value matrix

\begin{tabular}{cccccc}
\hline Alternatives & DP & I & CY & F & Weighted sum value \\
\hline DP & 0.651439 & 0.808301 & 0.957672 & 0.450817 & 2.868229 \\
I & 0.130288 & 0.16166 & 0.27362 & 0.150272 & 0.715841 \\
CY & 0.093063 & 0.08083 & 0.13681 & 0.250454 & 0.561157 \\
F & 0.072382 & 0.053887 & 0.027362 & 0.050091 & 0.203722 \\
\hline
\end{tabular}

Table 18. Computing ratio of weighted sum value and criteria value

\begin{tabular}{ccccccccc}
\hline & DP & I & CY & F & Weighted sum & \multicolumn{2}{c}{$\begin{array}{l}\text { Criteria } \\
\text { Veights }\end{array}$} & $\begin{array}{l}\text { Weighted sum } \\
\text { value/Criteria weights }\end{array}$ \\
\hline DP & 0.651439 & 0.808301 & 0.957672 & 0.450817 & 2.868229 & 0.651439 & $2.868229 / 0.651439$ \\
I & 0.130288 & 0.16166 & 0.27362 & 0.150272 & 0.715841 & 0.16166 & $0.715841 / 0.16166$ \\
CY & 0.093063 & 0.08083 & 0.13681 & 0.250454 & 0.561157 & 0.13681 & $0.561157 / 0.13681$ & 4.428055 \\
F & 0.072382 & 0.053887 & 0.027362 & 0.050091 & 0.203722 & 0.050091 & $0.203722 / 0.050091$ & 4.067049 \\
\hline
\end{tabular}

$(\lambda \max )=4.402914+4.428055+4.101716+4.067049 / 4=4.249933$

Consistency Index $(C I)=(\lambda \max -n) /(n-1)=4.249933-4 / 4-1=0.083311$

Consistency ratio $(C R)=$ consistency index $(C I) /$ random index $(R I)=0.083311 / 0.946=$ 0.088066

Is less than 0.10. As per [25], the Oak Ridge value for random index is 0.946 therefore this value has been used in the calculation. Consistency ratio $(C R)=0.088066=8.8 \%$. This indicates that the results are consistent and can be used for further decision-making related to the proposed work.

\section{ANALYSIS OF THE RESULTS FOR LEVEL 2 PROPOSED WORK}

By observing Table 19, it can be concluded that 11 agro-meteorological parameters will be able to contribute highest to diseases and pest management followed by irrigation management with fertilization management being the lowest one. Figure 6 shows the AHP software-based priorities and ranking of alternatives on level 2. AHP software calculated consistency ratio (CR) is $8.7 \%$ and 4.237 is principal Eigenvalue.

Table 19. Comparisons of manually and AHP software calculated criteria weights for level 2

\begin{tabular}{ccc}
\hline Parameter & Manually calculated criteria weights & AHP software calculated criteria weights \\
\hline Parameters prioritization for alternatives & 100.00 & 100.00 \\
Location & 65.1439 & 66.1 \\
Phenological week & 16.166 & 16.4 \\
Cropping season & 13.681 & 12.8 \\
Soil type & 5.0091 & 4.7 \\
& $100 \%$ & $100 \%$ \\
\hline
\end{tabular}

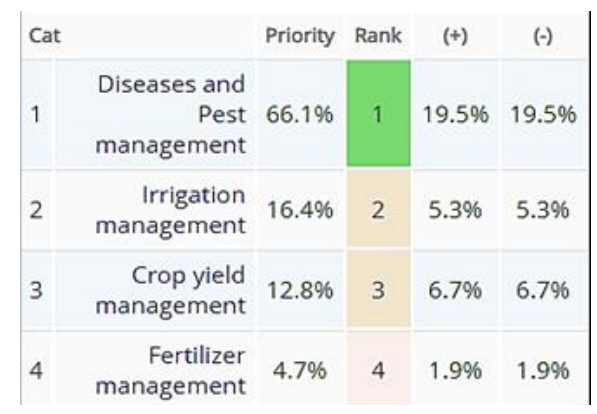

Figure 6. AHP software-based priorities and ranking of alternatives (Source: AHP online system-AHP-OS) 


\section{CONCLUSION}

The acquired results depict a good application of AHP to prioritize the agro-meteorological parameters to manage the plant diseases and pest, its irrigation requirements, its yielding capacity, and requirement of fertilization. It can be concluded that parameters like Location and phonological week are top in the order of priority, temperature, relative humidity, and rain are at mid in priority order while cloud coverage is the least contributing factor in integrated plant disease management. In the alternative level, the importance of parameters can be affected to take decisions related to plant diseases and pests while fertilization management decisions are not much affected with the agro-meteorological parameters. In this paper, results are verified for both the levels i.e level of parameters and second level of alternatives in AHP model for proposed work. This is done by comparing the results of manual calculations with AHP software generated priorities and ranking. It can be concluded that the results are like each other. The priorities and the rankings received from the AHP model for the problem under consideration can be further used to forecast or predict the occurrence of diseases and pests well beforehand so that preventive measures can be taken and therefore can increase the profit of the farmers.

\section{REFERENCES}

[1] B. Naseri, Hemmati, and Roghayeh, "Bean root rot management: Recommendations based on an integrated approach for plant disease control,” Rhizosphere, vol. 4, pp. 48-53, 2017, doi: 10.1016/j.rhisph.2017.07.001.

[2] B. Naseri, "Linkages of Farmers' operations with rhizoctonia root rot spread in bean crops on a regional basis," Journal of Phytopathology, vol. 161, no. 11-12, 2013, doi: 10.1111/jph.12140.

[3] L. K. Dhaliwal and S. K. Sandhu, "Identification of different agro meteorological parameters responsible for enhancing sheath blight severity in the field," Journal of Agrometeorology, vol. 14, pp. 201-206, 2012.

[4] T. L. Saaty, "Decision-making with the AHP: Why is the principal eigenvector necessary," European Journal of Operational Research, vol. 145, no. 1, pp. 85-91, 2003, doi: 10.1016/S0377-2217(02)00227-8.

[5] Y. L. Alaoui, "Introduction to MCDM techniques: AHP as example," Conference: Seminar at Islamic Financial Engineering laboratory, 2019, doi: 10.13140/RG.2.2.15536.30724.

[6] H. L. Napitupulu, "Determining the priority level of suppliers by using AHP and TOPSIS," IOP Conference Series: Materials Science and Engineering, vol. 505, no. 1, 2019, Art. no. 012154.

[7] S. Parthasarathy and S. Sharma, "Determining ERP customization choices using nominal group technique and analytical hierarchy process," Computers in Industry, vol. 65, no. 6, pp. 1009-1017, 2014, doi: 10.1016/j.compind.2014.03.003.

[8] G. Tian, H. Zhang, M. Zhou, and Z. Li, “AHP, gray correlation, and TOPSIS combined approach to green performance evaluation of design alternatives," IEEE Transactions on Systems, Man, and Cybernetics: Systems, vol. 48, no. 7, pp. 1093-1105, 2018, doi: 10.1109/TSMC.2016.2640179.

[9] X. Xu, Y. Wang, and S. Yu, "Teaching performance evaluation in smart campus,” IEEE Access, vol. 6, pp. 77754-77766, 2018, doi: 10.1109/ACCESS.2018.2884022.

[10] C. T. Chang, W. X. Zhao, and J. Hajiyev, "An Integrated smartphone and tariff plan selection for taxi service operators: MCDM and RStudio approach," IEEE Access, vol. 7, pp. 31457-31472, 2019, doi: 10.1109/ACCESS.2019.2903201.

[11] Z. Ren, Z. Xu, and H. Wang, "The strategy selection problem on artificial intelligence with an integrated VIKOR and AHP method under probabilistic dual hesitant fuzzy information," IEEE Access, vol. 7, pp. 103979-103999, 2019, doi: 10.1109/ACCESS.2019.2931405.

[12] G. Akman, "Evaluating suppliers to include green supplier development programs via fuzzy c-means and VIKOR methods," Computers and Industrial Engineering, vol. 86, pp. 69-82, 2015, doi: 10.1016/j.cie.2014.10.013.

[13] H. Zhang, G. Zhang, and Q. Jia, "Landslide susceptibility index based landslide susceptibility assessment of the pearl river," IEEE Journal of Selected Topics in Applied Earth Observations and Remote Sensin, vol. 12, no. 11, pp. 4239-4251, 2019.

[14] G. Zhang, H. Jia, L. Yang, Y. Li, and J. Yang, "Research on a model of node and path selection for traffic network congestion evacuation based on complex network theory," IEEE Access, vol. 8, pp. 7506-7517, 2020, doi: 10.1109/ACCESS.2019.2959654.

[15] A. Muhammad, A. Shaikh, Q. N. Naveed, and M. R. N. Qureshi, "Factors affecting academic integrity in e-learning of Saudi Arabian Universities: an investigation using Delphi and AHP," IEEE Access, vol. 8, pp. 16259-16268, 2020, doi: 10.1109/ACCESS.2020.2967499.

[16] A. E. Youssef, "An integrated MCDM approach for cloud service selection based on TOPSIS and BWM," IEEE Access, vol. 8, pp. 71851-71865, 2020, doi: 10.1109/ACCESS.2020.2987111.

[17] G. Rathee, S. Garg, G. Kaddoum, B. J. Choi, and M. S. Hossain, "Trusted orchestration for smart decision-making in internet of vehicles," IEEE Access, vol. 8, pp. 157427-157436, 2020, doi: 10.1109/ACCESS.2020.3019795.

[18] F. A. Al-Zahrani, "Evaluating the usable-security of healthcare software through unified technique of fuzzy logic, ANP and TOPSIS," IEEE Access, vol. 8, pp. 109905-109916, 2020, doi: 10.1109/ACCESS.2020.3001996.

[19] R. Jagabandhu and S. Saha," Assessment of land suitability for the paddy cultivation using analytical hierarchical process (AHP): a study on Hinglo river basin, Eastern India," Modeling Earth Systems and Environment, vol. 4, pp. 601-618, 2018.

[20] R. Patil and S. Kumar, "A bibliometric survey on the diagnosis of plant leaf diseases using artificial intelligence," International Journal of Modern Agriculture, vol. 9, no. 3, pp. 1111-1131, 2020.

[21] R. Patil, A. Jagtap, and R. Joshi, "Integrated Management system for sugarcane disease using deep learning techniques-a review," International Journal of Scientific and Technology Research, vol. 8, no. 11, pp. 1133-1137, 2019.

[22] P. Sharma, B. K. Singh, and R. P. Singh, "Prediction of potato late blight disease based upon weather parameters using artificial neural network approach," 2018 9th International Conference on Computing, Communication and Networking Technologies (ICCCNT), 2018, pp. 1-13, doi: 10.1109/ICCCNT.2018.8494024.

[23] S. M. Gaikwad, P. Mulay, and R. R. Joshi, "Analytical hierarchy process to recommend an ice cream to a diabetic patient based on sugar content in it," Procedia Computer Science, vol. 50, pp. 64-72, 2015, doi: 10.1016/j.procs.2015.04.062.

[24] K. Gospel, "Implementation of an online software tool for the analytic hierarchy process (AHP-OS)," International Journal of the Analytic Hierarchy Process, vol. 10, no. 3, pp. 469-487, 2018, doi: 10.13033/ijahp.v10i3.590.

[25] J. A. Alonso and M. T. Lamata, "Consistency in the analytic hierarchy process: A new approach," International Journal of Uncertainty Fuzziness and Knowledge-Based Systems, vol. 14, no. 4, pp. 445-459, 2006, doi: 10.1142/S0218488506004114. 